\title{
Deep and surface learning in problem-based learning: a review of the literature
}

\author{
Diana H. J. M. Dolmans ${ }^{1}$ - Sofie M. M. Loyens ${ }^{2,6}$ • \\ Hélène Marcq ${ }^{4} \cdot$ David Gijbels $^{5}$
}

Received: 25 September 2014/ Accepted: 21 October 2015/Published online: 13 November 2015

(C) The Author(s) 2015. This article is published with open access at Springerlink.com

\begin{abstract}
In problem-based learning (PBL), implemented worldwide, students learn by discussing professionally relevant problems enhancing application and integration of knowledge, which is assumed to encourage students towards a deep learning approach in which students are intrinsically interested and try to understand what is being studied. This review investigates: (1) the effects of PBL on students' deep and surface approaches to learning, (2) whether and why these effects do differ across (a) the context of the learning environment (single vs. curriculum wide implementation), and (b) study quality. Studies were searched dealing with PBL and students' approaches to learning. Twenty-one studies were included. The results indicate that PBL does enhance deep learning with a small positive average effect size of .11 and a positive effect in eleven of the 21 studies. Four studies show a decrease in deep learning and six studies show no effect. PBL does not seem to have an effect on surface learning as indicated by a very small average effect size (.08) and eleven studies showing no increase in the surface approach. Six studies demonstrate a decrease and four an increase in surface learning. It is concluded that PBL does seem to enhance deep learning and has little effect on surface learning, although more longitudinal research using high quality measurement instruments is needed to support this conclusion with stronger evidence. Differences cannot be explained by the study quality but a curriculum wide implementation of
\end{abstract}

Diana H. J. M. Dolmans

d.dolmans@maastrichtuniversity.nl

1 Department of Educational Development and Research, School of Health Professions Education (SHE), Faculty of Health, Medicine and Life Sciences (FHML), Maastricht University, PO Box 616, 6200 MD Maastricht, The Netherlands

2 Institute of Psychology, Erasmus University Rotterdam, Rotterdam, The Netherlands

3 Louvain School of Management, Louvain-La-Neuve, Belgium

4 Management of Learning, Maastricht University, Maastricht, The Netherlands

5 Department of Training and Education, EduBROn research group, Faculty of Social Sciences, University of Antwerp, Antwerp, Belgium

6 Roosevelt Center for Excellence in Education, University College Roosevelt, Middelburg, The Netherlands 
PBL has a more positive impact on the deep approach (effect size .18) compared to an implementation within a single course (effect size of -.05). PBL is assumed to enhance active learning and students' intrinsic motivation, which enhances deep learning. A high perceived workload and assessment that is perceived as not rewarding deep learning are assumed to enhance surface learning.

Keywords Problem-based learning - Deep approach · Surface approach · Students' approaches to learning (SAL)

\section{Introduction}

Universities are facing challenges today in educating students to become life-long learners and versatile experts in their own fields. Fostering and stimulating the development of lifelong learning skills such as problem solving and critical thinking has become a crucial goal of higher education in the twentyfirst century. According to the Bologna declaration, successful learning and studying in higher education should involve students in deep learning (Asikainen 2014). In a recent literature review, Dinsmore and Alexander (2012) state that if research on students' learning is going to have any bearing on practice, one area in need of critical discussion is the investigation of deep and surface learning. From their review, Dinsmore and Alexander (2012) identified why the results of studies on deep and surface learning often result in ambiguous and inconsistent findings. One of the reasons is that the conceptualization of deep and surface learning differs across studies as well as the way in which these concepts are measured. Often evidence of the validity of the instruments used to measure deep learning is lacking. Another reason is that the contexts in which the studies are conducted often vary, whereas deep learning might differ across contexts and academic domains. As a consequence, Dinsmore and Alexander (2012) emphasized from their review that it is important in future research to (a) clearly define what is meant by deep learning, starting from a clear theoretical framework, (b) investigate deep learning within a specific learning context, since the context of the learning environment may influence deep learning, and (c) measure deep learning by means of valid tools. In the present review-study, we aim to take these recommendations into account.

Below we will first explain the framework of students' approaches to learning (SAL) as the theoretical framework guiding this study. Next, we will elaborate on problem-based learning (PBL) as the learning context under study. Finally, we will explain how we have taken the issue of valid tools into account and we will present the central research questions of this review.

\section{Students' approaches to learning as a theoretical framework}

Theoretically, we build on the framework of students' approaches to learning (SAL). The concept of a deep approach to learning originated in the work of Marton and Säljö (1976). They discovered that students had different intentions when approaching a particular task (i.e., studying a text for later use). Some students intended to understand the meaning of the text, while others primarily wanted to be able to reproduce what they had read when questioned on it. Students with an intention to extract meaning from their readings were likely to try to relate information to prior knowledge, to structure ideas into comprehensible wholes, and to critically evaluate knowledge and conclusions presented in the text. Students who took upon themselves the task of committing text to memory were likely to 
use processing strategies such as rote learning. The former combination of intentions and processing strategies became known as a deep approach to learning and the latter as a surface approach. Trigwell et al. (2005) argue that students with a deep approach to learning are intrinsically interested and try to understand what they study. Students adopting a surface approach mainly focus on rote learning and primarily study to pass the test. Deep and surface approaches to learning are seen as a combination of students' intentions (or motives) and the accompanying learning activities. A surface approach to learning has typically been defined as an intention to reproduce content, with learning processes characterized by rote learning and memorization. A deep approach to learning has been described as a student's intention to understand content together with the processes of relating and structuring ideas, looking for underlying principles, weighing relevant evidence, and critically evaluating knowledge (Biggs et al. 2001; Entwistle and McCune 2004; Lonka and Lindblom-Ylänne 1996; Loyens et al. 2013). Approaches to learning are assumed to be related to the perceived demands of the learning environment and are not seen as purely personal characteristics (Biggs and Tang 2007; Nijhuis et al. 2005). How students approach their learning is viewed as changeable and influenced by factors in the learning environment, students' perceptions of these factors and student characteristics such as their prior knowledge on the topic under study (Gijbels et al. 2014). This is where the concept of approaches to learning differs from the concept of learning styles in which all learners are claimed to have their own personal and stable learning style that should be aligned to instruction. The field of learning styles has recently been heavily critiqued because of the lack of solid evidence that learning styles-as stable individual characteristics-actually exists (see e.g. Kirschner and Van Merriënboer 2013). However, research that investigated the kind of learning approaches that are used by students in university education has led to contradictory results (see e.g., Gijbels et al. 2009; Struyven et al. 2006; Wilson and Fowler 2005). Baeten et al. (2010) reviewed 25 studies to detect which factors encourage or discourage a deep approach to learning in student-centered learning environments in general. Their review demonstrated that characteristics of the teaching method, how students perceive the teaching context, and student factors play a role. Baeten et al. (2010) concluded that many of these factors are intertwined and that still little is known about how they relate to each other and differ across different studentcentered learning environments. The aim of the present paper is to overcome this problem of inconsistency and ambiguity in the empirical research on deep and surface approaches to learning and contribute to our understanding of students' learning in higher education. Numerous attempts have been made to optimize students' learning in higher education towards more deep and less surface approaches by means of implementing innovative teaching methods (e.g., Struyven et al. 2006; Wilson and Fowler 2005). We present a review study on students' approaches to learning conducted within the context of one specific learning environment in which students' approaches to learning have been studied extensively: problem-based learning (Loyens et al. 2013).

\section{Problem-based learning}

Problem-based learning (PBL) is a student-centered instructional approach that is implemented at many universities worldwide. PBL students discuss professionally relevant problems in small groups. The problems are first discussed before any preparation or selfstudy has taken place to activate students' prior knowledge. Because students' prior knowledge is insufficient to fully understand the problem, questions (i.e., learning issues) are formulated for further individual self-study by the students in the group. After this 
individual self-study period (i.e., 2 or 3 days later), students gather again and discuss what they have learned and come to an answer to the formulated learning issues. The group discussion is facilitated by a teacher (i.e., so-called tutor) and is aimed to acquire knowledge, to better understand the problem, and to acquire skills to solve the problem (Barrows 1996). PBL does, on the one hand, actively engage students in their own learning and, on the other hand, includes many scaffolds to enhance student learning such as carefully designed problems and a group discussion facilitated by a tutor. The design of the PBL process (i.e., a pre-discussion of the problem to activate prior knowledge and formulate learning issues, an individual self-study time period, and a reporting phase in which different literature findings are discussed and integrated) is well aligned with current instructional design approaches that emphasize the importance of learning by means of whole problems in order to avoid fragmentation and encourage integration of knowledge, skills, and attitudes (Merrill 2012; Van Merrienboer and Kirschner 2013). Instead of learning small parts piece by piece, PBL emphasizes the integration of knowledge and skills. For example, discussing literature findings within a group makes that the answers to the learning issues become illuminated from different angles, since during the individual self-study period, students have-to a certain extent and within the boundaries of the problem's topic-freedom to select and study their own literature resources. Besides learning content knowledge during the reporting phase, students also learn how to understand the underlying mechanisms of the problem at hand and hence, their problemsolving skills get trained at the same time. In other words, since students discuss relationships between concepts and principles, integrate different literature resources, apply these concepts and principles to the problems that are discussed in the group, and integrate knowledge and skills, PBL is assumed to encourage a deep approach to learning.

\section{The present study}

The present review study is aimed at investigating the effects of PBL on deep and surface learning. We define deep learning in terms of students approaches to learning, reflecting both intentions or motives and actual strategies. We consider a deep learning approach as being intrinsically interested and aimed at trying to understand what is being studied. A surface approach is defined as an intention and strategy that is mainly aimed at rote learning and studying to pass the test. So, this review does start from a theoretical framework in which deep and surface learning approaches are seen as a combination of students' intentions and accompanying learning activities, which are assumed to be related to the learning environment and are not seen as purely personal characteristics. In this review we focus on studies conducted in a problem-based learning environment. In line with earlier reviews on the effects of PBL (e.g., Dochy et al. 2003) we distinguish between either a curriculum wide or single course PBL implementation. In addition, when reviewing the relevant papers we will focus on the validity of the tools used to measure deep and surface approaches as well as the type of design or methodological quality of the studies. In this way, our study aims to meet the recommendations made by Dinsmore and Alexander (2012) mentioned earlier. The research questions addressed in this study are:

1. What are the effects of problem-based learning on students' deep and surface approaches to learning?

2. Do the effects differ across (a) the context of the learning environment (single course vs. curriculum wide implementations of PBL), and (b) study quality (methodologically high level quality of studies vs. low/medium quality studies)? 


\section{Methods}

According to the Campbell Collaboration, a systematic review of the literature should include (1) clear criteria for inclusion, (2) a clear search strategy (3) systematic coding and (4) a systematic analyses of the included studies, using meta-analyses techniques were appropriate (www.campbellcollaboration.org). We will discuss below how we have taken these four recommendations into account in our review of the literature.

\section{Criteria for inclusion}

Several criteria were defined for inclusion of studies in our review. First, the study should be conducted in a problem-based learning environment that is characterized by: (a) learning in small groups, (b) a teacher/tutor facilitating group learning, (c) the learning process is initiated by problems, and (d) new information is acquired through self-study (Barrows 1996). Second, each study should contain empirical data dealing with a deep or surface approach to learning. We did not restrict our studies to studies in which PBL curricula were compared with other curricula, nor did we restrict to quantitative studies; we included studies using different methodologies.

\section{Literature search}

Studies published between 1900 and 2015 were searched. The following data-bases were used: EBSCO, PUBMED, and Web of Science. The keywords used were: problem based learning, PBL, problem oriented learning, POL, problem-based approach, problem-based learning program, and PBLP in combination with deep learning, deep-rooted learning, deep understanding, rote learning, surface learning, and superficial learning. The studies were selected based on title and abstract. Based upon reading these studies, 21 papers were included in this review. Reasons for rejection of papers were because of not reporting effects on deep or surface learning, not focusing on PBL as defined earlier, and not including data (book chapters/commentaries).

\section{Coding study characteristics}

Based on our research questions, we developed a scheme to code and summarize all studies included. The following information was summarized: authors, journal, publication year, purpose, full PBL or hybrid curriculum, single course or curriculum wide implementation, study design, instruments, subjects, main conclusions, explanations of results, and suggestions for future research (see "Appendix"). The summaries were made by one of the authors (HM) and read by all other authors. The first author (DD) modified the summaries for those parts that were not yet clearly summarized in the opinion of the other authors. Subsequently, three authors (DD, SL, and DG) coded the papers based on the written summary. Each author coded whether the study dealt with PBL or a hybrid course/curriculum, whether the study dealt with a single course or curriculum wide implementation, whether it was a quantitative, qualitative or mixed-methods study, a one group (1 point) or experimental-control group design ( 2 points), a post-test only (1 point) or pre-post-test design (2 points), a longitudinal study (i.e., at least three measurement moments) (1) or not (0), whether the sample size was adequate (1) or not (0) (i.e., at least 40 subjects for the quantitative data), the instrument was tested to be reliable; e.g., reliability coefficients of 
.70 or higher (1), the instrument was tested to be valid; factor analysis confirmed the underlying factors (1). The overall study quality was rated based on the points that were received; a total score of 3 or lower was considered to be a study with low quality; a score of 4 and 5 as moderate, and a score of 6 till 8 as high quality. In addition, each study was scored in terms of its effect on deep learning: increase/positive $(+)$, no effect $(0)$ or decrease/negative (-). Similarly, each study was scored in terms of its effect on surface learning: increase/negative (+), no effect (0), decrease/positive (-). Finally, factors influencing approaches to learning were summarized in words. The coding was done by three authors (DD, SL, and DG). Disagreements were resolved through discussion.

Table 1 Effects of PBL on deep and surface approaches to learning across full PBL or hybrid PBL and across studies conducted in a single course PBL environment versus a curriculum wide PBL implementation

\begin{tabular}{|c|c|c|c|c|}
\hline Study nr & $\begin{array}{l}\text { Full PBL or hybrid } \\
\text { PBL }\end{array}$ & $\begin{array}{l}\text { Single course or } \\
\text { curriculum wide PBL }\end{array}$ & $\begin{array}{l}\text { Deep aproach } \\
\text { (ES) }\end{array}$ & $\begin{array}{l}\text { Surface approach } \\
\text { (ES) }\end{array}$ \\
\hline 1 & PBL computer & Course & Increase $(0.93)$ & Decrease $(-0.50)$ \\
\hline 2 & PBL & Curriculum & Decrease $(-0.53)$ & Increase $(0.50)$ \\
\hline 3 & Hybrid & Curriculum & Increase $(0.33)$ & No effect $(-0.28)$ \\
\hline 4 & PBL & Course & No effect $(0.00)$ & No effect $(0.13)$ \\
\hline 5 & PBL & Course & Decrease $(-0.38)$ & Increase $(0.50)$ \\
\hline 6 & PBL & Curriculum & Decrease $(-0.36)$ & No effect $(0.23)$ \\
\hline 7 & PBL & Curriculum & Increase $(0.16)$ & Increase $(0.24)$ \\
\hline 8 & PBL & Curriculum & Increase & Decrease \\
\hline 9 & PBL & Curriculum & Increase $(-0.41)$ & No effect $(0.23)$ \\
\hline 10 & Hybrid & Curriculum & No effect $(0.44)$ & No effect $(-0.45)$ \\
\hline 11 & PBL & Course & No effect $(0.00)$ & No effect $(-0.03)$ \\
\hline 12 & PBL & Course & Increase & No effect \\
\hline 13 & PBL & Course & No effect & No effect \\
\hline 14 & PBL & Course & Increase & Decrease \\
\hline 15 & PBL & Curriculum & Increase $(0.23)$ & No effect $(0.10)$ \\
\hline 16 & PBL & Curriculum & Decrease $(-0.38)$ & Increase $(0.50)$ \\
\hline 17 & Hybrid & Course & $\begin{array}{r}\text { No effect } \\
(-0.17)\end{array}$ & No effect $(-0.07)$ \\
\hline 18 & PBL & Course & Increase $(0.29)$ & No effect $(-0.17)$ \\
\hline 19 & PBL & Curriculum & Increase $(0.21)$ & Decrease $(0.36)$ \\
\hline 20 & PBL & Curriculum & No effect & Decrease \\
\hline 21 & PBL & Curriculum & Increase $(0.50)$ & Decrease $(0.00)$ \\
\hline $\begin{array}{l}\text { Total } \\
\qquad(n=21)\end{array}$ & $\begin{array}{l}\text { PBL }(n=17) \\
\text { Hybrid }(n=3) \\
\text { Computer }(n=1)\end{array}$ & $\begin{array}{l}\text { Curriculum wide } \\
\quad(n=12) \\
\text { Single course }(n=9)\end{array}$ & $\begin{array}{l}\text { Increase } \\
\quad(n=11) \\
\text { Decrease }(n=4) \\
\text { No effect }(n=6)\end{array}$ & $\begin{array}{l}\text { Increase }(n=4) \\
\text { Decrease }(n=6) \\
\text { No effect }(n=11)\end{array}$ \\
\hline
\end{tabular}

ES: effect size (Cohen's d) calculated if possible based on Lipsey and Wilson (2001)

${ }^{a}$ Deep approach: increase/positive, no effect, decrease/negative effect

b Surface approach: increase/negative effect, no effect, decrease/positive effect 


\section{Synthesizing research}

For our purposes, a systematic review of the literature was conducted accompanied by the vote counting method and the associated sign test (Cooper et al. 2009; Hedges and Olkin 1980). If the original studies reported the necessary information, also effect sizes were calculated for each individual study based on the standardized mean differences following Lipsey and Wilson (2001).

\section{Results}

\section{What are the effects of PBL on deep and surface approaches to learning?}

Table 1 provides an overview of the 21 studies. As can be seen in the final row of this Table 1, 17 studies were conducted in a full PBL environment, 3 in a hybrid PBL environment and 1 in a PBL computer environment. Furthermore, 12 studies were done in a curriculum wide PBL implementation and nine in a single course PBL environment. Table 1 also demonstrates that PBL does enhance a deep approach to learning in eleven studies. PBL does lead to a decrease in deep approach in four studies and has no effect on deep approach in another six studies. Furthermore, it is shown in Table 1 that PBL has no effect on a surface approach to learning in eleven studies. PBL does lead to a decrease in surface learning in six studies and an increase in four studies.

Table 2 presents the result of the vote-counts, sign test and effect sizes in order to give an answer on our first research question related to the main effects of PBL on deep and surface approaches to learning (Cooper et al. 2009). The vote count in Table 2 shows a positive tendency for the effects of PBL on deep learning with eleven studies of the 21 yielding a positive effect (i.e., a higher score or increase in the learning approach which we will label in the remaining of the text as 'increase') compared to four studies yielding a negative effect (i.e., a lower score or decrease in the learning approach which we will label in the remaining of the text as 'decrease'). It should be mentioned, however, that this difference between studies fostering and lowering a deep approach to learning, was not statistically significant. The average effect size of .11 points towards a small positive effect of PBL on the deep approach.

As for the effects of PBL on surface learning approaches, eleven studies show no effect on surface learning, six studies show a lower score or decrease and four studies an increase in surface learning. Again, the two-sided sign-test was not significant for the number of

Table 2 Main effects of PBL: vote counts and effect sizes

\begin{tabular}{lllll}
\hline Outcome & Significance & Significance & No effect & Effect size \\
\hline Deep approach $^{\mathrm{a}}$ & $11^{\mathrm{ns}}$ increase & 4 decrease & 6 & 0.11 \\
Surface approach $^{\mathrm{b}}$ & $6^{\mathrm{ns}}$ decrease & 4 increase & 11 & 0.08 \\
\hline
\end{tabular}

Sign. number of studies with an increase/decrease in deep and surface approach to study

Studies $(n)$ the number of total non-independent outcomes measured

ns Two-sided sign-test is not significant at the $5 \%$ level 
studies decreasing and increasing a surface approach to learning and also the average effect size of .08 indicates that PBL has little effect on the surface approach.

\section{Does context or study quality impact deep learning?}

In Table 3 the effects of studies reporting positive, negative or no effects on deep and surface approaches to learning across studies conducted in a curriculum wide PBL implementation $(n=12)$ and a single course PBL implementation $(n=9)$ are reported. The vote count indicated that for curriculum wide PBL implementations, seven studies showed an increase in deep learning, three studies led to a decrease in deep learning and two studies showed no effect. The effect size of .18 indicates a small effect of PBL in a curriculum wide implementation on students' deep approach. Four studies indicated a decrease in surface learning, whereas three studies showed an increase in surface approach and another five studies no effect. However, the two-sided sign-tests were not significant for both the effects on deep and surface approaches to learning, meaning that the difference in number of studies reporting an increase and decrease in both deep and surface approaches to learning, is not statistically significant. Also the effect size of .08 gives an indication that a curriculum wide implementation of PBL has little effect on the surface approach.

The bottom part of Table 3 reports the effects on deep and surface approaches to learning across studies conducted in a single PBL course $(n=9)$. The vote count showed that four studies showed an increase in deep learning, one study led to a decrease on deep learning and four studies showed no effect. Table 3 also demonstrates that two studies showed a decrease in surface learning, one study gave evidence of an increase in surface approach and another six studies showed no effects. Similarly to the results for curriculum wide implementations, the two-sided sign-tests were not significant for both the effects on deep and surface approaches to learning. Hence, the difference in number of studies fostering or hindering both deep and surface approaches to learning was not statistically significant. However, for single course PBL implementations, the majority of the studies did not show an effect on surface approaches to learning. The effect sizes for both the deep $(-0.05)$ and the surface $(.07)$ approach are close to zero for the single course implementation of PBL.

Table 3 Effects of PBL curriculum wide and single course implementations: vote counts and effect sizes

\begin{tabular}{llllr}
\hline Outcome & Significance & Significance & No effect & Effect size \\
\hline Curriculum wide $(n=12)$ & & & \\
Deep approach & $7^{\text {ns }}$ increase & 3 decrease & 2 & 0.18 \\
Surface approach & $4^{\text {ns }}$ decrease & 3 increase & 5 & 0.08 \\
Single course PBL $(n=9)$ & & & 4 & -0.05 \\
Deep approach & $4^{\text {ns }}$ decrease & 1 decrease & 4 & 0.07 \\
Surface approach & $2^{\text {ns }}$ decrease & 1 increase & 6 & \\
\hline
\end{tabular}

Sign. number of studies with an increase/decrease in deep and surface approach to study

Studies $(n)$ the number of total non-independent outcomes measured

ns Two-sided sign-test is not significant at the $5 \%$ level 
In Table 4 the methodological quality of the studies is summarized. As can be seen from this table, the majority of the studies were quantitative studies $(n=18)$ and a minority were mixed-methods studies $(n=3)$. In terms of study designs, eleven studies involved experimental control group studies and ten studies used a one group design. In total, 14 pre-post test study designs were used and seven post-test only designs. Only one study was a longitudinal study with three measurement moments. The sample size was clearly above 40 in 16 out of 21 studies. The majority of the studies did make use of the Study Process Questionnaire developed by John Biggs and colleagues (11 studies). Only three studies reported about the validity of the instrument used and seven studies about the reliability of the data. In total, eight studies had a high overall study quality score (a score of 5, 6 or 7).

The effects of PBL on deep and surface learning depending on study quality are mentioned in Table 5. For high-quality studies $(n=8)$, the vote count showed that three studies showed an increase in deep learning, one study led to a decrease on deep learning

Table 4 Summary of methodological quality of the studies

\begin{tabular}{|c|c|c|c|c|c|c|c|c|}
\hline & $\begin{array}{l}\text { Design: } \\
\text { quantitative } \\
\text { qualitative } \\
\text { mixed methods } \\
\text { (MM) }\end{array}$ & $\begin{array}{l}\text { Design: one } \\
\text { group (1) or } \\
\text { exp-control } \\
\text { group (2) }\end{array}$ & $\begin{array}{l}\text { Design: } \\
\text { post only } \\
(1) \text { or pre- } \\
\text { post (2) }\end{array}$ & $\begin{array}{l}\text { Sample } \\
\text { size } \\
\text { adequate } \\
\text { no (0) } \\
\text { yes (1) at } \\
\text { least } 40\end{array}$ & $\begin{array}{l}\text { Instru- } \\
\text { ment }\end{array}$ & $\begin{array}{l}\text { Valid } \\
\text { no }(0) \\
\text { yes } \\
(1)\end{array}$ & $\begin{array}{l}\text { Relia- } \\
\text { ble no } \\
\text { (0) yes } \\
\text { (1) }\end{array}$ & $\begin{array}{l}\text { Overall } \\
\text { study } \\
\text { quality }^{\text {a }}\end{array}$ \\
\hline 1 & Quantitative & One & Pre-post & Yes & LAQ & No & Yes & 5 \\
\hline 2 & Quantitative & Exp-control & Pre-post & Yes & ASSIST & Yes & Yes & 7 \\
\hline 3 & Quantitative & Exp-control & Post only & Yes & SIAL & No & No & 4 \\
\hline 4 & Quantitative & One & Pre-post & Yes & SPQ & No & Yes & 5 \\
\hline 5 & Quantitative & Exp-control & Post only & Yes & SPQ & No & No & 4 \\
\hline 6 & Quantitative & One & Pre-post & Yes & SPQ & No & No & 4 \\
\hline 7 & Quantitative & One & Pre-post & Yes & SPQ & No & Yes & 5 \\
\hline 8 & Quantitative & Exp-control & Post only & Yes & SPQ & No & No & 4 \\
\hline 9 & Mixed & Exp-control & Post only & Yes & ALSI & No & No & 4 \\
\hline $10^{\mathrm{b}}$ & Quantitative & One & Pre-post & No & ASSIST & No & Yes & 5 \\
\hline 11 & Quantitative & Exp-control & Pre-post & Yes & SPQ & No & No & 5 \\
\hline 12 & Quantitative & Exp-control & Pre-post & No & ALS & No & No & 4 \\
\hline 13 & Quantitative & One & Pre-post & No & SPQ & No & No & 3 \\
\hline 14 & Mixed & One & Post only & No & SPQ & No & No & 2 \\
\hline 15 & Mixed & One & Pre-post & Yes & SPQ & Yes & Yes & 6 \\
\hline 16 & Quantitative & Exp-control & Post only & Yes & SPQ & No & No & 4 \\
\hline 17 & Quantitative & Exp-control & Pre-post & Yes & ASSIST & Yes & Yes & 7 \\
\hline 18 & Quantitative & One & Pre-post & Yes & SIAL & No & No & 4 \\
\hline 19 & Quantitative & Exp-control & Post only & Yes & LASI & No & No & 4 \\
\hline 20 & Quantitative & Exp-control & Pre-post & $\begin{array}{l}\text { Not } \\
\text { given }\end{array}$ & ASSI & No & No & 4 \\
\hline 21 & Quantitative & One & Pre-post & Yes & ASSI & No & No & 4 \\
\hline
\end{tabular}

\footnotetext{
${ }^{a}$ The overall study quality was calculated based on the scores received for the study design, sample size, validity and reliability of the data. There was one longitudinal study see ${ }^{\mathrm{b}}$ with three measurement moments, which received one extra score
} 
and four studies showed no effect. The effect size of .13 points towards a small positive effect. With respect to surface learning, two studies showed a decrease, one study an increase and five no effect. The effect size was with -.01 close to zero. Similar to the results regarding the scale of PBL implementation, the two-sided sign-tests were not significant for both the effects on deep and surface approaches to learning.

In the bottom part of Table 5, results are mentioned for low and medium quality studies $(n=13)$. Seven studies gave evidence of an increase in deep learning, four studies led to a decrease on deep learning and two studies showed no effect. The effect size of .07 indicates there is no or a very small effect. For surface approaches to learning, six studies showed a decrease, one study showed an increase and six studies showed no effects. For mediumlow quality studies, although almost half of the studies found no effect on surface approaches to learning, the effect size of .17 points towards a meaningful effect.

Again, the two-sided sign-tests were not significant for both the effects on deep and surface approaches to learning, meaning no differences could be found in the number of studies showing an increase versus a decrease for both deep and surface approaches to learning.

\section{Conclusion and discussion}

This review was aimed at investigating the effects of PBL on deep and surface approaches to learning. The studies included were all conducted within the specific context of PBL and most of the studies used Biggs' theoretical framework to measure deep and surface processing. Dinsmore and Alexander (2012) made a plea to study deep learning approaches from a clear theoretical framework and within a specific context; a specific learning environment. We addressed these points in this review. The review demonstrated that eleven of the 21 the studies give indications that PBL does encourage a deep approach to learning and in eleven of the 21 studies measuring surface learning, PBL had no effect on a surface approach. As also indicated by the effect sizes, PBL does seem to enhance deep learning to some extent $(\mathrm{ES}=.11)$ and has less effect on surface learning $(\mathrm{ES}=.08)$. Furthermore, this review demonstrated that differences in effects between the studies could be partly explained by differential characteristics of the environment in which the PBL studies were conducted (a curriculum wide implementation has a more positive impact on

Table 5 Effects of PBL depending on study quality: vote counts and effect sizes

\begin{tabular}{|c|c|c|c|c|}
\hline Outcome & Significance & Significance & No effect & ES \\
\hline \multicolumn{5}{|c|}{ High-quality studies $(n=8)$} \\
\hline Deep approach $^{\mathrm{a}}$ & $3^{\text {ns }}$ increase & 1 increase & 4 & 0.13 \\
\hline Surface approach $^{\mathrm{b}}$ & $2^{\text {ns }}$ decrease & 1 decrease & 5 & -0.01 \\
\hline \multicolumn{5}{|c|}{ Medium-low quality studies $(n=13)$} \\
\hline Deep approach $^{\mathrm{a}}$ & $7^{\mathrm{ns}}$ increase & 4 decrease & 2 & 0.07 \\
\hline Surface approach ${ }^{\mathrm{b}}$ & $6^{\mathrm{ns}}$ decrease & 1 increase & 6 & 0.17 \\
\hline
\end{tabular}

Sign. number of studies with a significant increase or decrease in deep and surface approach to study Studies $(n)$ the number of total non-independent outcomes measured

ns Two-sided sign-test is not significant at the $5 \%$ level 
students' deep approach $(\mathrm{ES}=.18)$ compared to a single course $(\mathrm{ES}=-.05)$ implementation), but not by study quality.

The mechanisms through which PBL is assumed to enhance deep learning are active and self-directed learning. PBL is considered an active form of learning, since students need to analyze, compare, contrast, and explain information (Serife 2011). They are actively involved in their learning process because they themselves need to develop and explain hypotheses for the problem at hand and search for evidence for these explanations and hypotheses, using various literature and other learning resources (Gurpinar et al. 2013). Self-directed learning comes into play in PBL since students take responsibility over their own learning. They have, to a certain degree and within the boundaries of the problem, the freedom to select their own resources to answer the learning issues, which gives them ownership over their learning. Eleven out of the 21 studies included in this review demonstrate that PBL does foster deep learning $(\mathrm{ES}=.11)$. This effect is possibly mediated through intrinsic motivation. A recent PBL study in which having the freedom to choose literature resources (i.e., self-directed condition) from a set was compared to a condition in which two literature resources were given to students, indeed demonstrated that students in the self-directed condition scored higher on autonomous motivation (Wijnia et al. 2015), giving evidence for the relationship between self-directed learning and autonomous/intrinsic motivation.

The findings of this review also indicate that PBL has little effect on surface learning in eleven out of 18 studies (ES $=.08$ ) measuring surface learning. Is this good news or not? It could be argued that this finding is in a way a positive effect too. Nevertheless we should also take into account that in some situations a surface approach or perhaps better a combination of a deep and surface approach should best be used to learn effectively (Dinsmore and Alexander 2012). A high perceived workload will more likely result in surface approaches to studying and might be detrimental for deep learning. Students who perceive the workload as high in their learning environment are more likely to display a lack of interest in their studies as well as exhaustion. This is particularly true for beginning PBL students (Litmanen et al. 2014). Another factor that can lead to more surface learning is the assessment methods used. If the assessment is perceived as not rewarding deep learning, students will rely on surface learning. Therefore, the role of assessment is important to take into account in studies on SAL. Entwistle et al. (2003, p. 90) state in this respect that research findings vary "due to differences in the extent to which understanding is explicitly rewarded in the assessment procedure". A qualitative study by Al Kadri et al. (2009) under PBL medical students confirmed indeed that students adapt their approaches to studying to the assessment demands (i.e. type of assessment and weight accorded to it). Scouller (1998) and Jensen et al. (2014) demonstrated that students were more likely to employ a deep approach when studying for assignment essays, which they perceived as measuring higher levels of cognitive processing, compared to a multiple choice assessment.

Although most studies demonstrate that PBL does enhance deep learning and has no effect on surface learning, this review also shows that studies often result in ambiguous and inconsistent findings as is also concluded by Dinsmore and Alexander (2012). One reason is that only three studies out of 21 studies reported about the validity of the data and eight about the reliability of the data. Often evidence of validity was lacking as concluded before by Dinsmore and Alexander (2012). Within this review we investigated deep learning within a specific context, being PBL. Although the studies demonstrated a trend towards a positive effect on deep learning and no effect on surface learning, findings differed across studies which could indicate that PBL is applied differently across the different studies, 
even although we included only studies in this review that met our definition of PBL. In addition, in one study it was argued that students already displayed high scores on deep learning due to which it might be difficult to further improve deep learning (Reid et al. 2005).

This review has several limitations. First of all, the studies included in this review only made use of self-report data; actual student behaviors were not measured and could differ from students' self-perceptions. Next, the relationship with academic achievement was not considered in this review. Further, the number of longitudinal studies and qualitative studies was limited and some studies included only one group (i.e., no control group) or only post-test data (i.e., no pre-test data) due to which no clear comparisons could be made. As mentioned, not all studies included reported data about the validity and reliability of the instruments used to measure deep and surface processing, although the majority of the studies used previously validated instruments. Not all the studies included in the review reported the necessary information to calculate effect sizes. Hence, effect sizes of only 16 studies were included and aggregated across different study designs. For future research, more longitudinal studies are needed to determine the long terms effects of PBL on deep and surface learning, as well as experimental studies with a control group and pre- and post measurements that can give better insight in the actual changes in students' deep and surface processing. Longitudinal studies provide opportunities to measure how approaches to learning might differ over time, although it should be taken into account that characteristics of the learning environment may also vary over time. Qualitative studies are needed as well since they could give us better insight in why and how PBL does or does not enhance deep and surface processing. Finally, future studies should report validity and reliability data of the instruments used to measure deep and surface processing.

Acknowledgments The contribution of David Gijbels to this paper is partly supported by the Research Fund of the University of Antwerp (Grant ID 30369). The contribution of Diana Dolmans to this paper is partly supported by the Limburg University Fund SWOL, Maastricht University, the Netherlands.

\section{Compliance with ethical standards}

Conflicts of interest None.

Open Access This article is distributed under the terms of the Creative Commons Attribution 4.0 International License (http://creativecommons.org/licenses/by/4.0/), which permits unrestricted use, distribution, and reproduction in any medium, provided you give appropriate credit to the original author(s) and the source, provide a link to the Creative Commons license, and indicate if changes were made.

\section{Appendix with summary of the 21 studies}




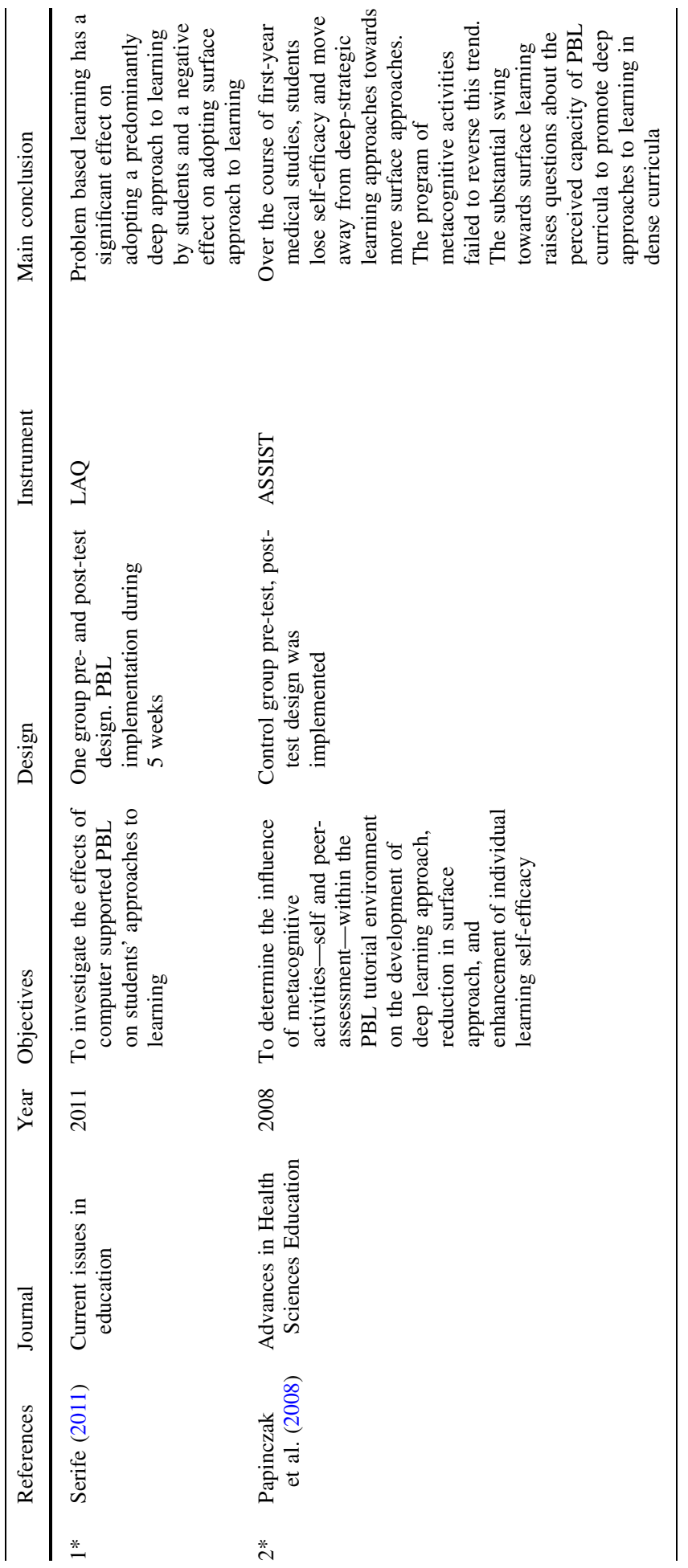




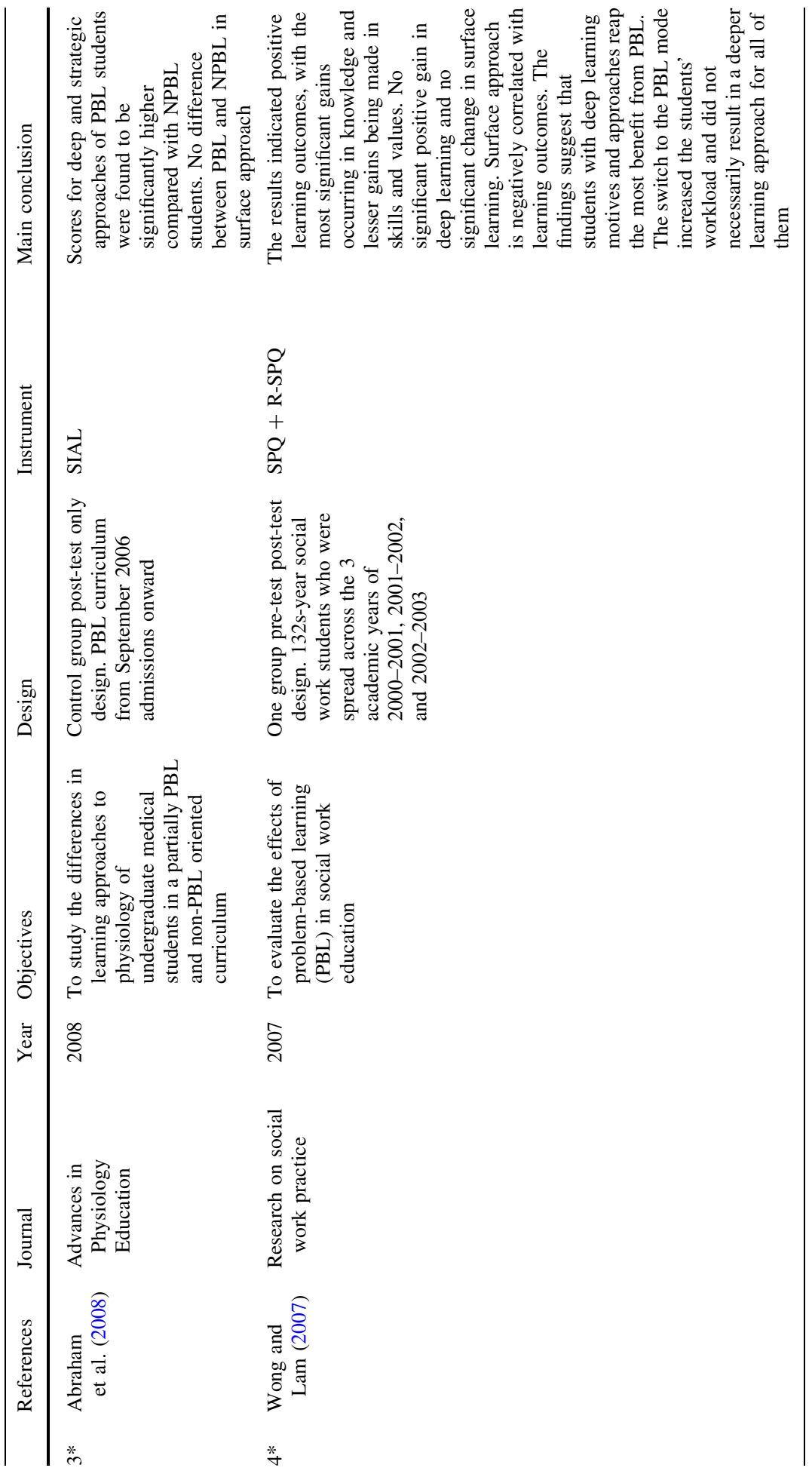




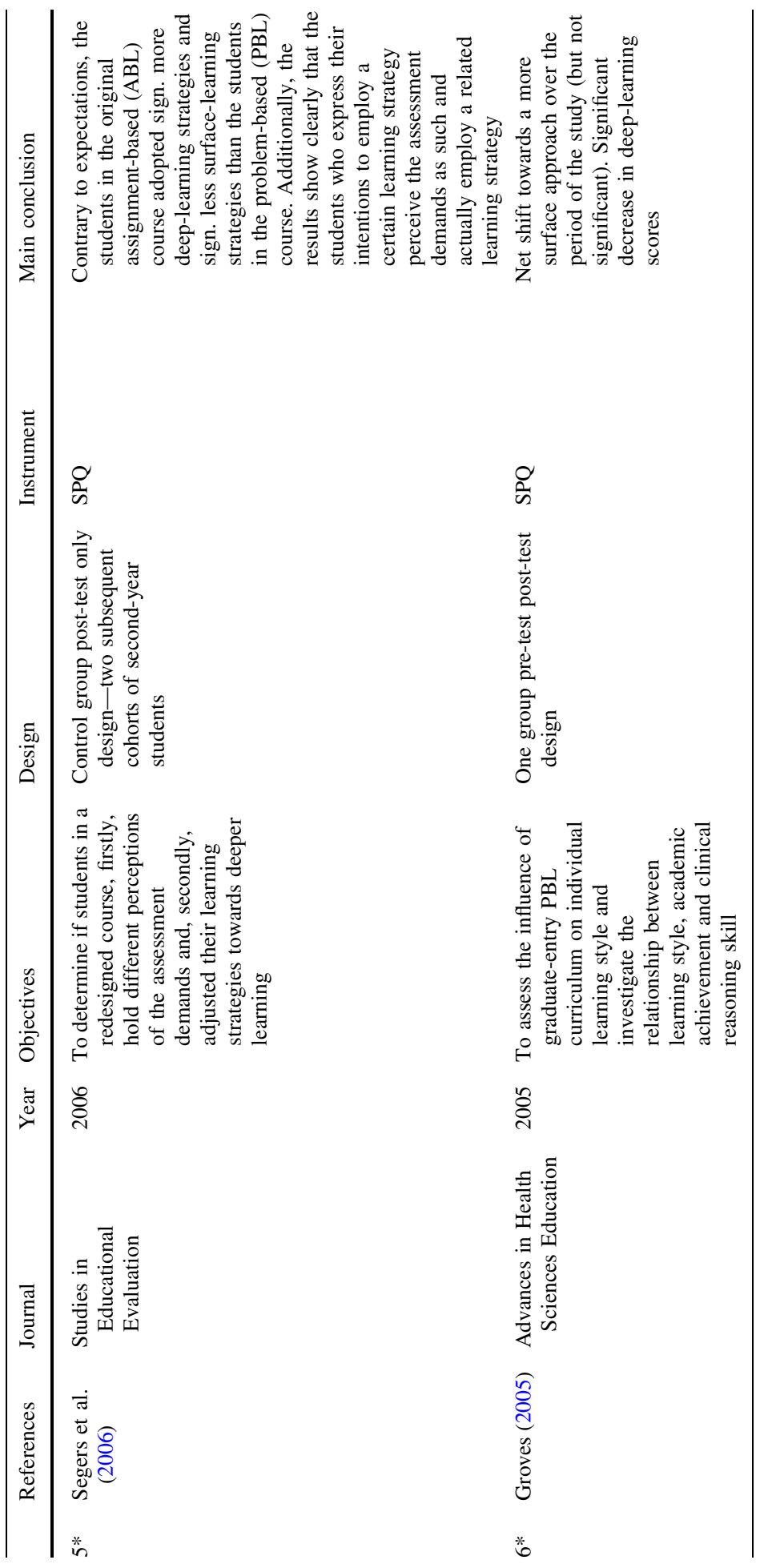




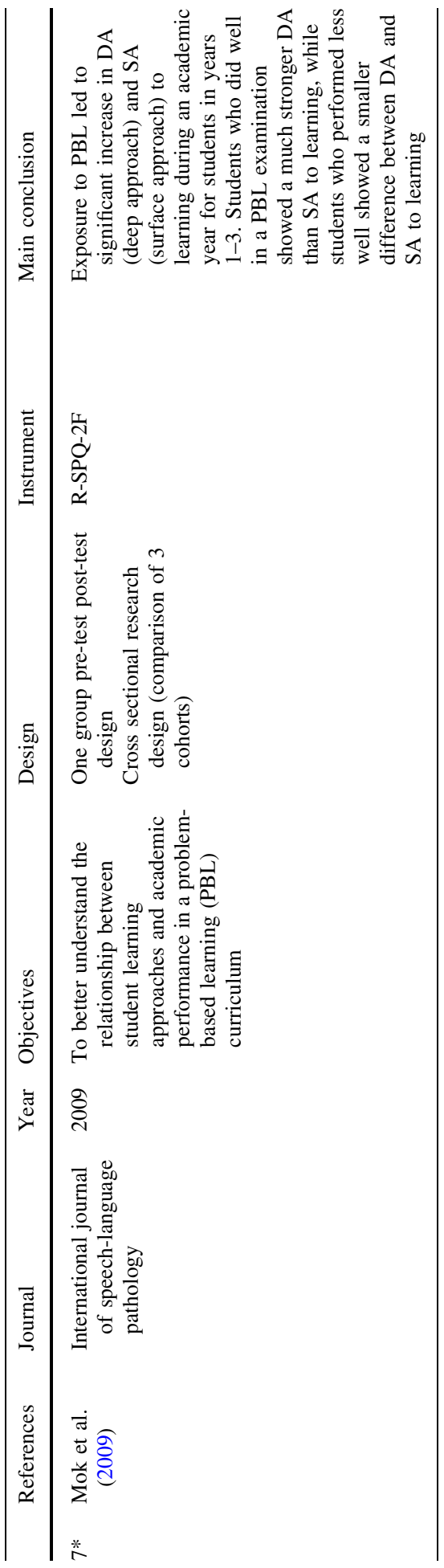




\begin{tabular}{|c|c|c|}
\hline & 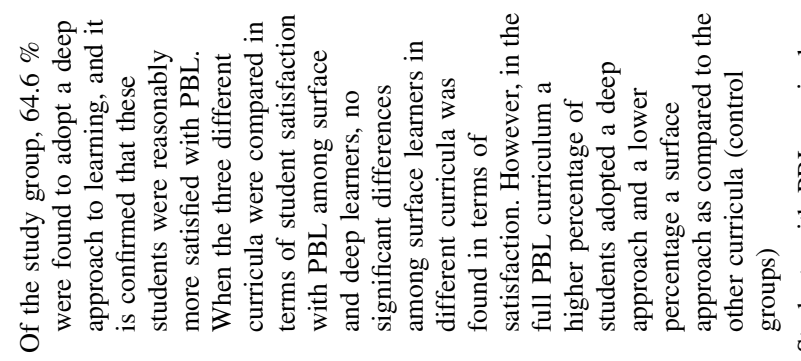 & 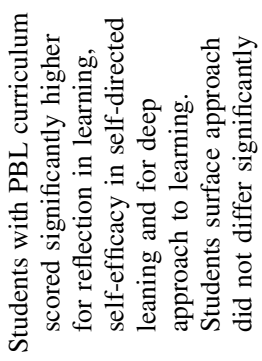 \\
\hline & 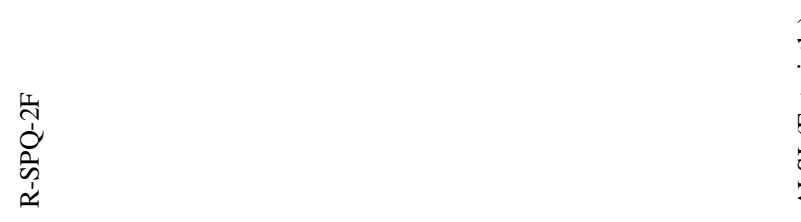 & 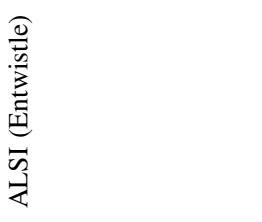 \\
\hline & 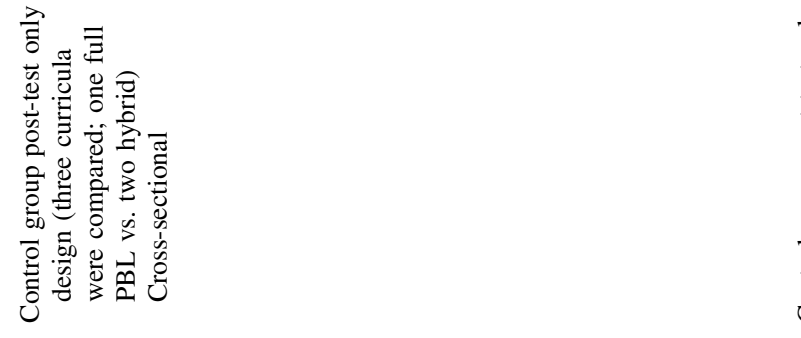 & 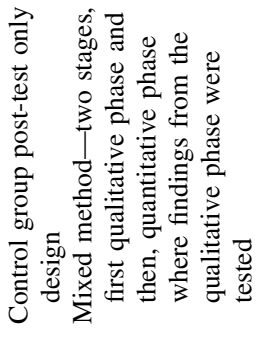 \\
\hline & 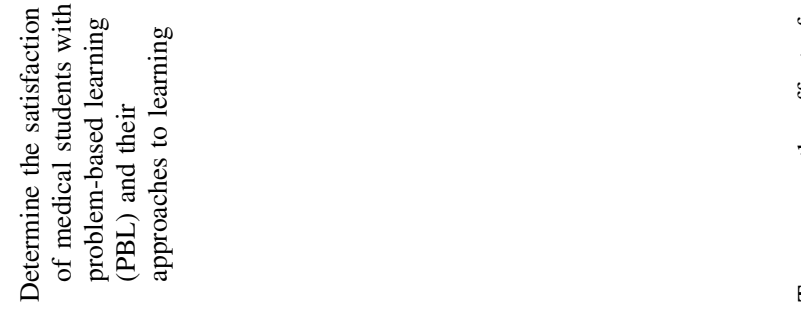 & 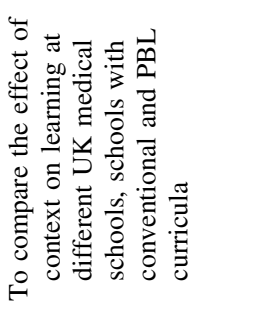 \\
\hline 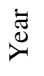 & $\stackrel{m}{\stackrel{n}{\sim}}$ & $\underset{\sim}{\stackrel{\sim}{\sim}}$ \\
\hline & 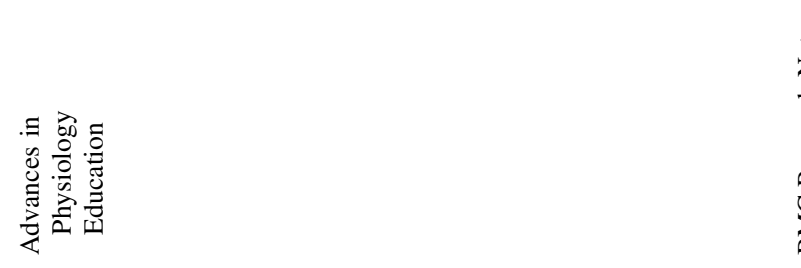 & 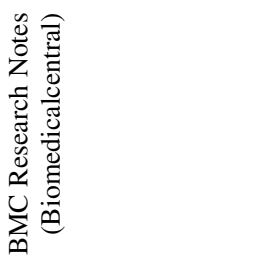 \\
\hline & 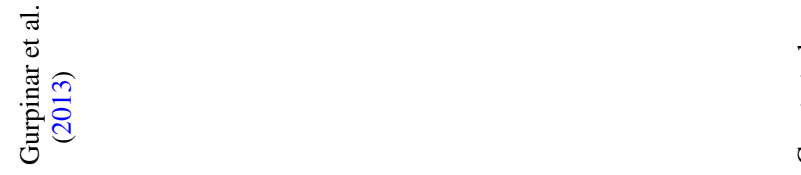 & 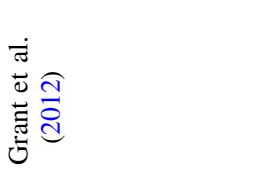 \\
\hline & ${ }_{\infty}^{*}$ & مै \\
\hline
\end{tabular}




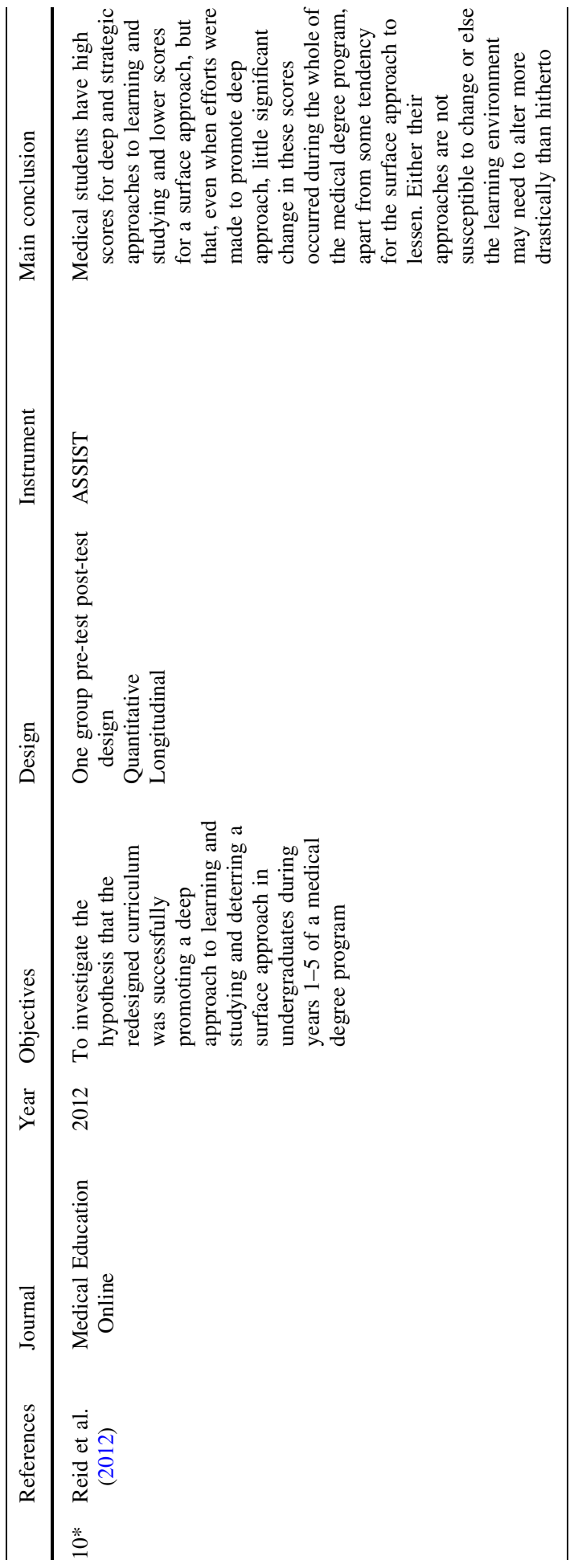




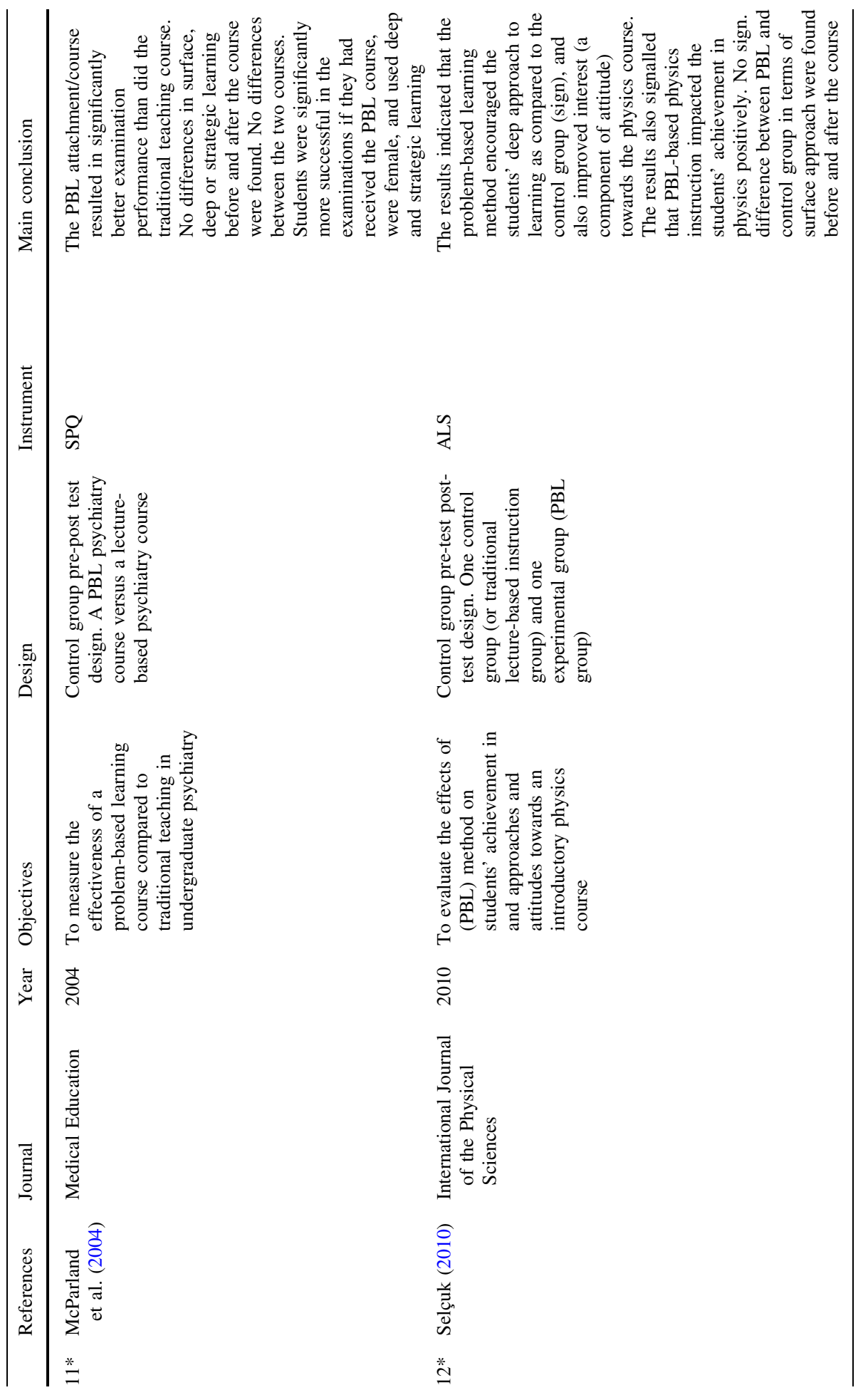




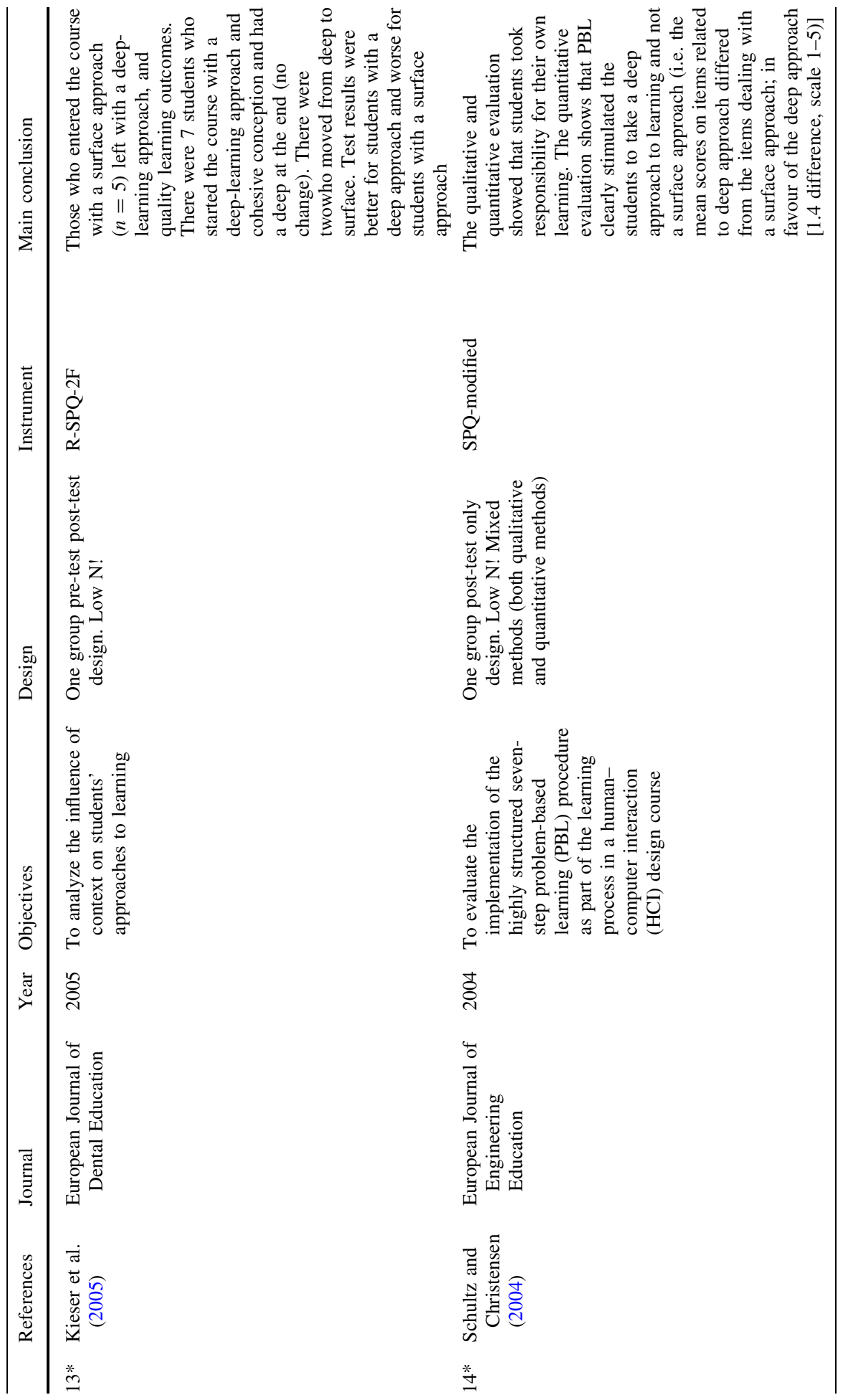




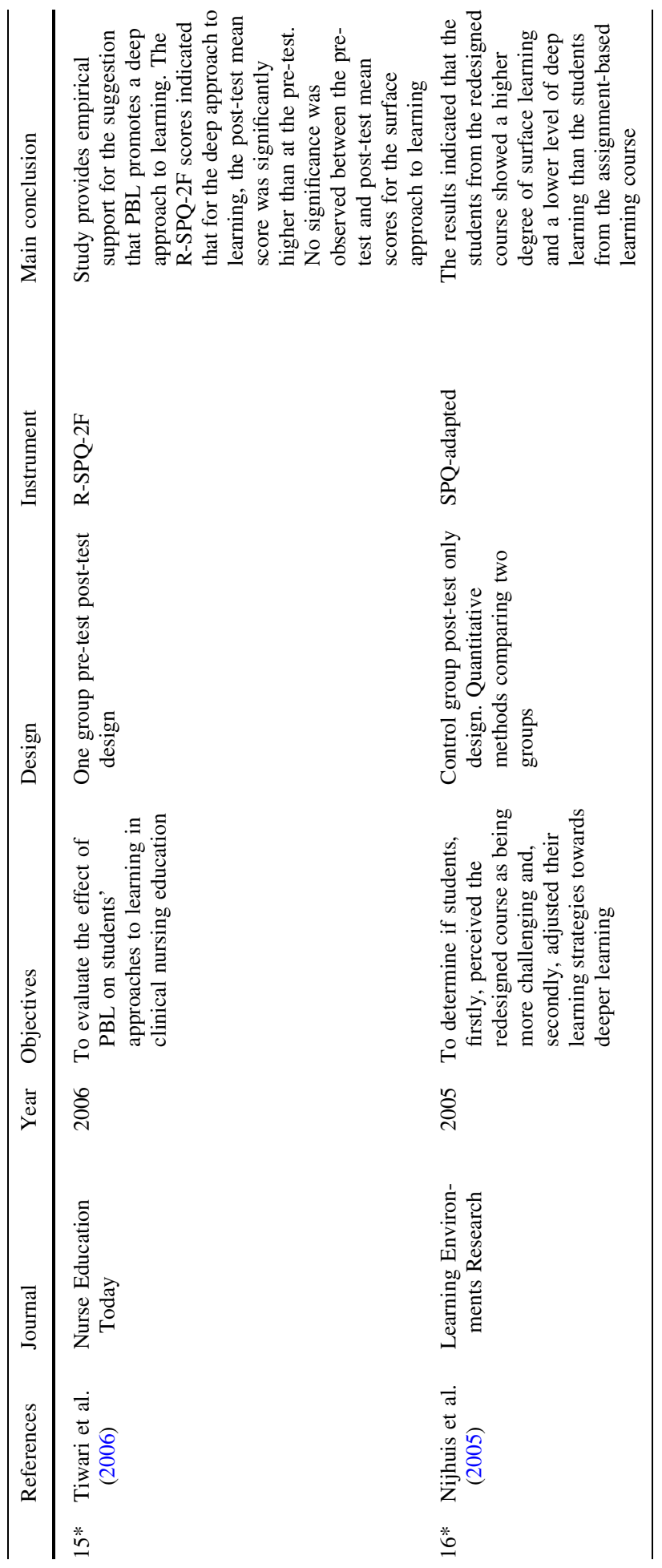




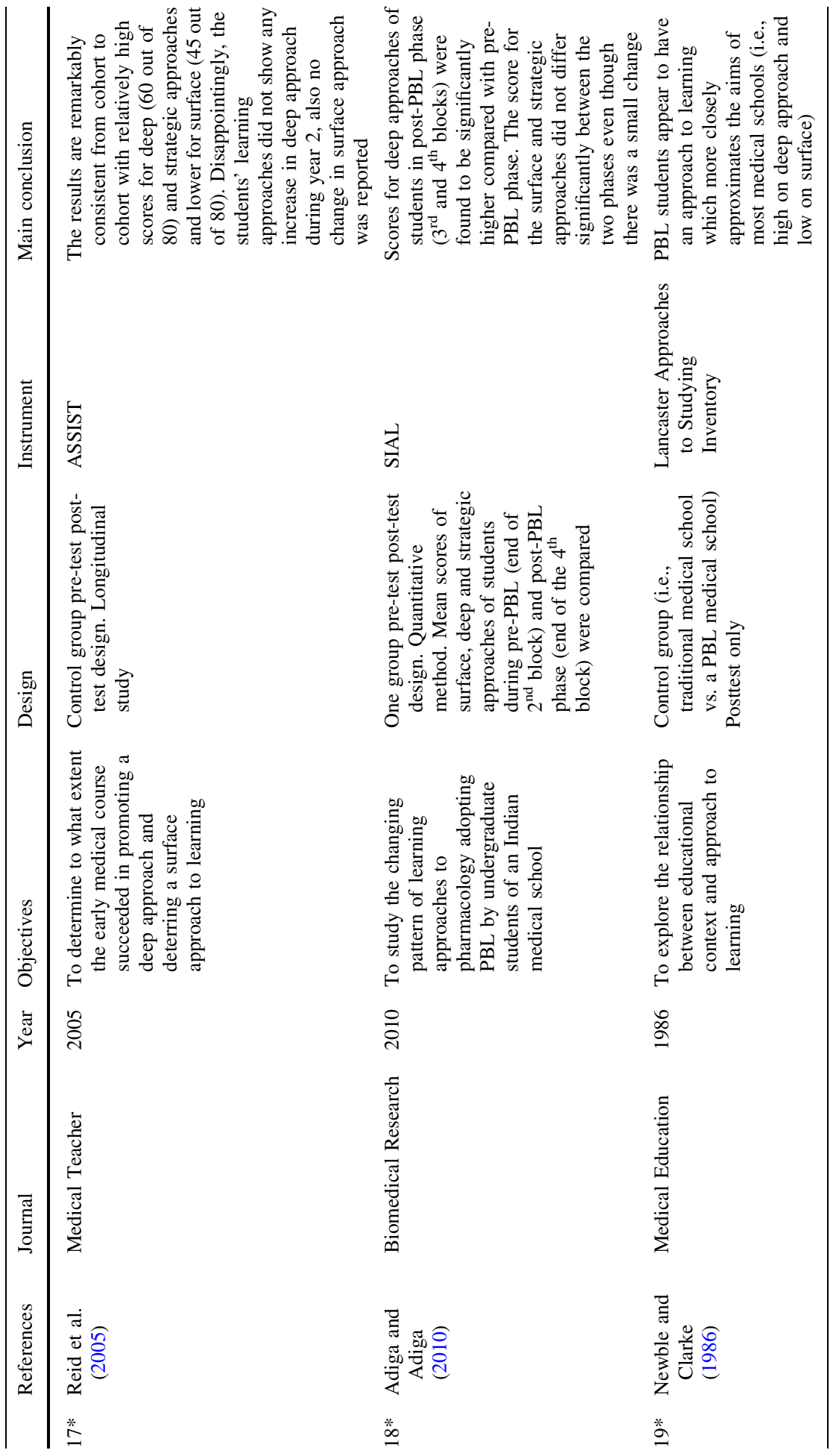




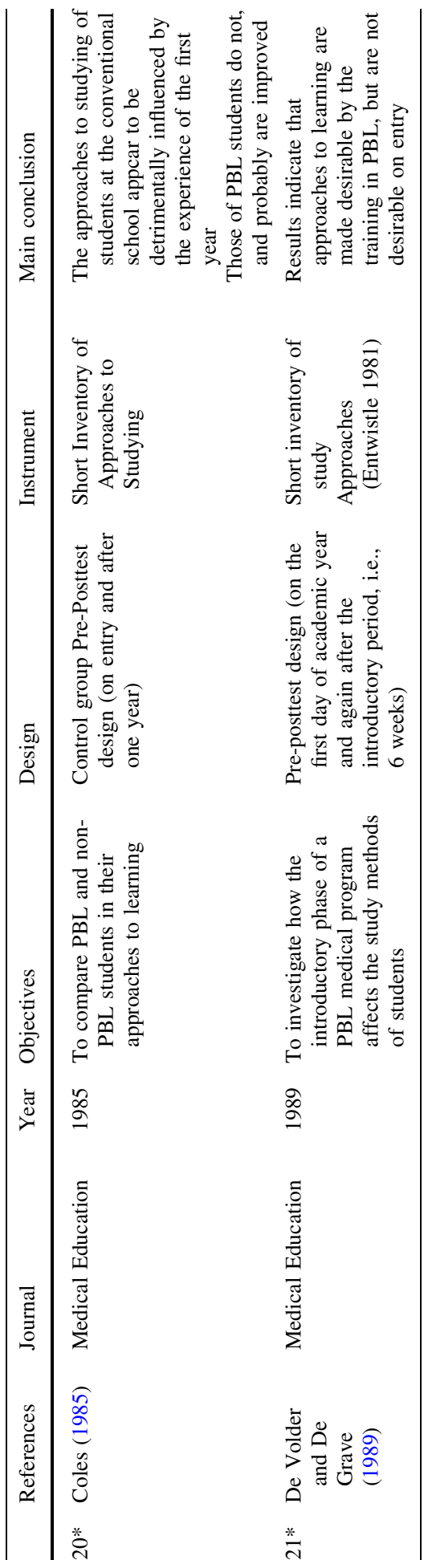




\section{References}

\section{*21 papers included in the review}

*Abraham, R. R., Vinod, P., Kamath, M. G., Asha, K., \& Ramnarayan, K. (2008). Learning approaches of undergraduate medical students to physiology in a non-PBL- and partially PBL-oriented curriculum. Advances in Physiology Education, 32, 35-37.

*Adiga, S., \& Adiga, U. (2010). Problem based learning-An approach to learning pharmacology in medical school. Biomedical Research, 21(1), 43-46.

Al Kadri, H. M., Al-Moamary, M. S., \& van der Vleuten, C. (2009). Students' and teachers' perceptions of clinical assessment program: A qualitative study in a PBL curriculum. BMC Research Notes, 2(1), 263.

Asikainen, H. (2014). Successful learning and studying in the biosciences. Exploring how students' conceptions of learning, approaches to learning, motivation and their experiences of the teaching-learning environment are related to study success. Helsinki: Unigrafia.

Baeten, M., Kyndt, E., Struyven, K., \& Dochy, F. (2010). Using student-centered learning environments to stimulate deep approaches to learning: Factors encouraging and discouraging their effectiveness. Educational Research Review, 5, 243-260. doi:10.1016/j.edurev.2010.06.001.

Barrows, H. S. (1996). Problem-based learning in medicine and beyond: A brief overview. In L. Wilkerson \& W. H. Gijselaers (Eds.), New directions for teaching and learning (Vol. 68, pp. 3-12). San Francisco: Jossey-Bass.

Biggs, J. B., Kember, D., \& Leung, D. Y. P. (2001). The revised two-factor study process questionnaire: R-SPQ-2F. British Journal of Educational Psychology, 71(1), 133-149.

Biggs, J. B., \& Tang, C. (2007). Teaching for quality learning at university. Berkshire: Open University Press/McGraw-Hill Education.

*Coles, C. R. (1985). Differences between conventional and problem-based curricula in their students' approaches to studying. Medical Education, 19, 308-309.

Cooper, H., Hedges, L. V., \& Valentine, J. C. (Eds.). (2009). The handbook of research synthesis and metaanalysis. New York City: Russell Sage Foundation.

*De Volder, M. L., \& De Grave, W. S. (1989). Approaches to learning in a problem-based medical programme: A developmental study. Medical Education, 23, 262-264.

Dinsmore, D. L., \& Alexander, P. A. (2012). A critical discussion of deep and surface processing: What it means, how it is measured, the role of context, and model specification. Educational Psychology Review, 24(4), 499-567.

Dochy, F., Segers, M., Van den Bossche, P., \& Gijbels, D. (2003). Effects of problem-based learning: A meta-analysis. Learning and Instruction, 13(5), 533-568.

Entwistle, N. J., \& McCune, V. (2004). The conceptual bases of study strategy inventories. Educational Psychology Review, 16, 325-345.

Entwistle, N. J., McCune, V., \& Hounsell, J. (2003). Investigating ways of enhancing university teachinglearning environments: Measuring students' approaches to studying and perceptions of teaching. In E. De Corte, L. Verschaffel, N. Entwistle, \& J. van Merrienboer (Eds.), Unravelling basic components and dimensions of powerful learning environments (pp. 89-107). Oxford: Elsevier Science.

Gijbels, D., Coertjens, L., Vanthournout, G., Struyf, E., \& Van Petegem, P. (2009). Changing students' approaches to learning: A two-year study within a university teacher training course. Educational Studies, 35(5), 503-513.

Gijbels, D., Donche, V., Richardson, J. T. E., \& Vermunt, J. D. (2014). Learning patterns in higher education. Dimensions and research perspectives. London: Routledge.

*Grant, A., Kinnersley, P., \& Field, M. (2012). Learning contexts at two UK medical schools: A comparative study using mixed methods. BMC Research Notes, 5, 153.

*Groves, M. (2005). Problem-based learning and learning approach: Is there a relationship ? Advances in Health Sciences Education, 10, 315-326.

*Gurpinar, E., Kulac, E., Tetik, C., Akdogan, I., \& Mamakli, S. (2013). Do learning approaches of medical students affect their satisfaction with problem-based learning? Advances in Physiology Education, 37, 85-88.

Hedges, L. V., \& Olkin, I. (1980). Vote counting methods in research synthesis. Psychological Bulletin, 88, 359-369.

Jensen, J. L., McDaniel, M. A., Woodard, S. M., \& Kummer, T. A. (2014). Teaching to the test... or testing to teach: Exams requiring higher order thinking skills encourage greater conceptual understanding. Educational Psychology Review, 26(2), 307-329. 
Kieser, J., Herbison, P., \& Harland, T. (2005). The influence of context on students' approaches to learning: A case study. Dental Education, 9, 150-156.

*Kirschner, P. A., \& van Merriënboer, J. J. G. (2013). Do learners really know best? Urban legends in education. Educational Psychologist, 48(3), 169-183.

Lipsey, M. W., \& Wilson, D. B. (2001). Practical meta-analysis. Thousand Oaks, Calif: Sage Publications.

Litmanen, T., Loyens, S. M. M., Sjöblom, K., \& Lonka, K. (2014). Medical students' perceptions of theirlearning environment, well-being and academic self-concept. Creative Education, 5(21), 1856.

Lonka, K., \& Lindblom-Ylänne, S. (1996). Epistemologies, conceptions of learning and study practices in medicine and psychology. Higher Education, 31, 5-24.

Loyens, S. M. M., Gijbels, D., Coertjens, L., \& Coté, D. (2013). Students' approaches to learning in problem-based learning: Taking into account students' behavior in the tutorial groups, self-study time, and different assessment aspects. Studies in Educational Evaluation, 39(1), 23-32. doi:10.1016/j. stueduc.2012.10.004.

Marton, F., \& Säljö, R. (1976). On qualitative differences in learning: I-Outcome and process. British Journal of Educational Psychology, 46(1), 4-11.

*McParland, M., Noble, L. M., \& Livingston, G. (2004). The effectiveness of problem-based learning compared to traditional teaching in undergraduate psychiatry. Medical Education, 38, 859-867.

Merrill, M. D. (2012). First principles of instruction. Hoboken: Wiley.

Mok, C. K. F., Dodd, B., \& Whitehill, T. L. (2009). Speech-language pathology students' approaches to learning in problem-based learning curriculum. International Journal of Speech-Language Pathology, 11(6), 472-481.

*Newble, D. I., \& Clarke, R. M. (1986). The approaches to learning of students in a traditional and in an innovative problem-based medical school. Medical Education, 20, 267-273.

*Nijhuis, J. F. H., Segers, M. S. R., \& Gijselaers, W. H. (2005). Influence of redesigning a learning environment on student perceptions and learning strategies. Learning Environments Research, 8, 67-93.

Papinczak, T., Young, L., Groves, M., \& Haynes, M. (2008). Effects of a metacognitive intervention on students' approaches to learning and self-efficacy in a first year medical course. Advances in Health Sciences Education, 13, 213-232.

*Reid, W. A., Duvall, E., \& Evans, P. (2005). Can we influence medical students' approaches to learning? Medical Teacher, 27(5), 401-407.

*Reid, W. A., Evans, P., \& Duvall, E. (2012). Medical students' approaches to learning over a full degree programme. Medical Education Online, 17, 17205.

*Schultz, N., \& Christensen, H. P. (2004). Seven-step problem-based learning in an interaction design course. European Journal of Engineering Education, 29(4), 533-554.

Scouller, K. M. (1998). The influence of assessment method on students' learning approaches: Multiple choice question examination versus assignment essay. Higher Education, 35, 453-472.

*Segers, M., Nijhuis, J., \& Gijselaers, W. (2006). Redesigning a learning and assessment environment: The influence on students'perceptions of assessment demands and their learning strategies. Studies in Educational Evaluation, 32, 223-242.

*Selçuk, G. S. (2010). The effects of problem-based learning on pre-service teachers' achievement, approaches and attitudes towards learning physics. International Journal of the Physical Sciences, 5(6), 711-723.

*Serife, A. K. (2011). The effects of computer supported problem based learning on students' approaches to learning. Current Issues in Education, 14, 1.

Struyven, K., Dochy, F., Janssens, S., \& Gielen, S. (2006). On the dynamics of students' approaches to learning: The effects of the teaching/learning environment. Learning and Instruction, 16(4), 279-294.

*Tiwari, A., Chan, S., Wong, E., Wong, D., Chui, C., Wong, A., \& Patil, N. (2006). The effect of problembased learning on students' approaches to learning in the context of clinical nursing education. Nurse Education Today, 26, 430-438.

Trigwell, K., Prosser, M., \& Ginns, P. (2005). Phenomenographic pedagogy and a revised approaches to teaching inventory. Higher Education Research and Development, 24, 349-360.

Van Merrienboer, J. J. G., \& Kirschner, P. A. (2013). Ten steps to complex learning ( $2^{\text {nd }}$ (2nd Rev ed.). New York: Routledge.

Wijnia, L., Loyens, S. M. M., Derous, E., \& Schmidt, H. G. (2015). How important are student-selected versus instructor-selected literature resources for students' learning and motivation in problem-based learning? Instructional Science. doi:10.1007/s11251-014-9325-6. 
Wilson, K., \& Fowler, J. (2005). Assessing the impact of learning environments on students' approaches to learning: Comparing conventional and action learning designs. Assessment \& Evaluation in Higher Education, 30(1), 87-101.

*Wong, D. K., \& Lam, D. O. B. (2007). Problem-based learning in social work: A study of student learning outcomes. Research on Social Work Practice, 17, 55. 